\title{
COCRIAÇÃO E COLABORAÇÃO: COMO FUNCIONA ESSA RELAÇÃO NO SEGMENTOO DE HOSPEDAGEM
}

\author{
CO-CREATION AND COLLABORATION: HOW DOES THIS \\ REALATION WORK IN THE ACCOMMODATION SEGMENT
}

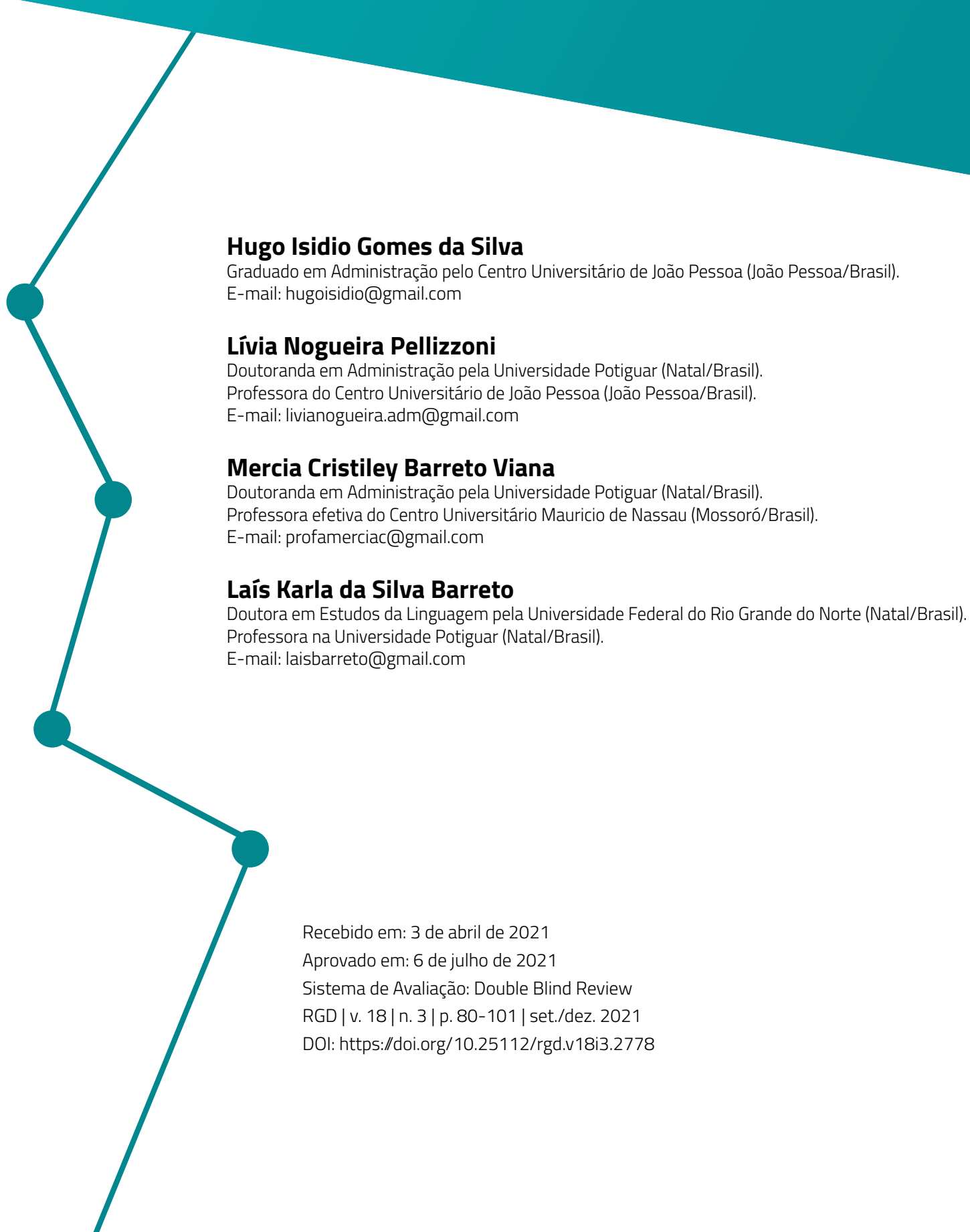




\section{RESUMO}

Com o desenvolvimento de novas tecnologias e redes de comunicação, bem como as limitações do modelo econômico tradicional frente às expectativas dos consumidores, o consumo colaborativo tem se mostrado como uma alternativa para a satisfação das necessidades de consumo. 0 presente trabalho tem como objetivo analisar quais aspectos da cocriação de valor mais influenciam consumidores de um negócio colaborativo de hospedagem. A pesquisa foi desenvolvida com a aplicação de questionário com 306 usuários da plataforma, sendo um estudo descritivo e com emprego de métodos de análises quantitativas para obtenção dos resultados. Os resultados apontaram que Transparência e Diálogo são os principais fatores de cocriação de valor dentro do segmento, sendo que pessoas do sexo feminino, mais jovens e com maiores rendas tendem a ser mais exigentes quanto às ferramentas de cocriação. Este estudo justifica-se à medida que surgem alterações comportamentais dos consumidores frente ao serviço de hospedagem, onde a possibilidade de interação em rede entre usuários e empresa tem gerado processos de cocriação de valor.

Palavras-chave: Consumo Colaborativo. Airbnb. Cocriação de valor.

\section{ABSTRACT}

With the development of new technologies and communication networks, as well as the limitations of the traditional economic model in the face of consumer expectations, collaborative consumption has proven to be an alternative to satisfy consumption needs. This paper aims to analyze which aspects of value co-creation most influence consumers of a collaborative hosting business. The research was developed with the application of a questionnaire with 306 users of the platform, being a descriptive study and using quantitative analysis methods to obtain the results. The results showed that Transparency and Dialogue are the main factors for the co-creation of value within the segment, with women, younger and with higher incomes, tend to be more demanding in terms of co-creation tools. This study is justified as the behavioral changes of consumers emerge regarding the hosting service, where the possibility of network interaction between users and the company has generated processes of co-creation of value.

Keywords: Collaborative Consumption. Airbnb. Value co-creation. 


\section{INTRODUÇÃO}

Diante da conjuntura econômica contemporânea, apresenta-se um mundo de experiências de participação, onde pessoas consomem, trocam, produzem e distribuem conteúdos e coisas, através da internet e de plataformas de compartilhamento. Esse estudo se interessa particularmente pelo processo de prática colaborativa, excepcionalmente na forma como as pessoas buscam vivenciar uma experiência em viagem através da utilização de uma plataforma de hospedagem específica: o Airbnb.

O desenvolvimento de tecnologias em redes e a interação entre as pessoas têm fomentado o crescimento do consumo colaborativo. Nesse modelo socioeconômico, busca-se o uso de recursos ociosos bem como as experiências de uso e acessos temporários ao invés da posse dos mesmos. Com as limitações do modelo tradicional de economia em relação às expectativas dos consumidores, o consumo colaborativo tem se mostrado como uma nova alternativa para a satisfação das necessidades de consumo. Essa modalidade de consumo em essência é um fenômeno que busca mudar a maneira como enxergamos a posse, priorizando ao invés dela, o acesso temporário feito de maneira eficiente (PISCICELLI; FISHER; COOPER, 2015).

E se pensarmos, no contexto da Pandemia da covid-19 veremos que muitos autores já enfatizam uma nova forma de pensar o turismo pós-pandemia (STANKOV et al., 2020). Isto se dá em função de tudo que a humanidade viveu, exercendo uma perspectiva de consumo no turismo mais consciente, mas próximo até do seu lugar de origem, conhecendo seu próprio país de forma mais colaborativa.

Estudos sobre a temática do consumo colaborativo têm surgido dado que essa nova forma de relacionamento entre as partes interessadas, tanto no ambiente físico quanto no digital (sites e plataformas de compartilhamento) vem alterando a forma de utilização e aquisição de bens e serviços. No âmbito empresarial, as empresas que possuem um ambiente propício a cocriação de valor, ganham força. Uma vez que, seu foco está direcionado nas experiências do consumidor.

Entre os serviços que preconizam o consumo colaborativo, uma plataforma que vem ganhando bastante destaque dentro do segmento de hospedagens, é a plataforma Airbnb. A mesma surge como uma alternativa para os viajantes que buscam mais que uma viagem econômica, mas o desejo de experimentar a cidade de forma autêntica, como um morador local, descobrindo bairros e regiões muitas vezes pouco exploradas pelo turismo tradicional (AIRBNB, 2018). Além disso os anfitriões são pessoas comuns que oferecem um cômodo de suas residências ou sua residência inteira para compartilhamento por tempo determinado com outras pessoas de forma intermediada pela plataforma.

O setor de serviços foi considerado o objeto de estudo que apresenta segmento econômico forte e com perspectivas de grande importância e significância para o desenvolvimento social (GRÖNROOS, 
2009). Logo, verifica-se a importância de compreender o comportamento desse novo tipo de consumidor de serviços envolvido nesses processos de colaboração, considerando a complexidade dos fatores envolvidos, uma vez que o uso do Airbnb no Brasil cresceu 71\% em 2018 (AIRBNB, 2018).

$O$ presente estudo tem como objetivo analisar quais aspectos da cocriação de valor mais influenciam o comportamento dos consumidores de um negócio colaborativo de hospedagem, mais especificamente o Airbnb. Para isso, utilizou-se como referência o bloco DART (Diálogo, Acesso, Avaliação de Risco e Transparência) desenvolvido por Prahalad e Ramaswamy (2004).

No que se refere à estrutura do artigo, primeiramente é apresentado uma revisão teórica contextualizando a temática do consumo colaborativo, a cocriação de valor e a plataforma de hospedagem Airbnb. Posteriormente, apresenta-se a metodologia utilizada para o desenvolvimento da pesquisa, seguindo com a discussão dos resultados. Por fim, conclui-se o trabalho com as considerações finais que possui contribuições e sugestões para futuros trabalhos.

\section{FUNDAMENTAÇÃO TEÓRICA}

\subsection{CONSUMO COLABORATIVO}

O consumo colaborativo apoia-se no fato de que haja algum benefício para os indivíduos que consomem, mas visando um benefício coletivo e ao ambiente no qual estão inseridos. Essa modalidade está diretamente ligada às formas de interação social. É um sistema socioeconômico baseado no uso compartilhado de alguns tipos de recursos (PISCICELLI; FISHER; COOPER, 2015).

Na literatura não existe ainda um consenso na definição de consumo colaborativo e, por isso, o termo é encontrado sob diversas nomenclaturas (BELK, 2014; BARDHI; ECKHARDT, 2012; LAMBERTON; ROSE, 2012; BOTSMAN; ROGERS, 2011; GANSKY, 2010). Mas, de modo geral, trata-se da descentralização da posse e do compartilhamento de serviços ou produtos. Bardhi e Eckhardt (2012, p. 881) definem o consumo colaborativo como sendo "consumo baseado em acesso". Dentro dessa definição podemos observar uma mudança no comportamento dos consumidores, nos quais estão cada vez mais voltados às experiências de uso e dos acessos temporários a bens e serviços do que à posse dos mesmos.

Essa modalidade de consumo, propõe a gestão eficaz do uso compartilhado de recursos ociosos, sejam eles, produtos, ativos ou serviços (ROSS; HAHN, 2017). Dessa forma, a ideia é a de que o consumidor gaste menos por algo que, de qualquer modo, só usaria por um tempo curto; e não se preocupe com esse bem quando não o está usando (BRAMBILLA et al., 2017). 
Para Piscicelli, Fisher e Cooper (2015) o consumo colaborativo é um modelo sócio econômico emergente, que por meio da interação com a comunidade e a utilização de tecnologias em rede, tem transformado os mercados tradicionais. E essas mudanças estão diretamente ligadas à nossa maneira de consumir. Um dos fatores para o fortalecimento dessa prática é o surgimento de plataformas digitais, nas quais os custos de transação são reduzidos pela ausência de intermediários e por cobrarem taxas de utilização bem inferiores às das empresas tradicionais. Além disso, fornecem aos consumidores o compartilhamento de uma grande variedade de produtos ou serviços, tornando mais eficiente as relações de consumo.

Conforme Bostman e Rogers (2011) o ato de compartilhar bens e serviços por meio de plataformas digitais têm transformado a economia e a forma de consumo das partes envolvidas no processo de compra ou utilização desses. Com o uso da Internet, estes compartilhamentos transcendem a esfera local. Ou seja, as transações podem ser realizadas a qualquer hora e em qualquer lugar. Nesse sistema, o foco das trocas é a interação social. Para essa interação social dentro dessa modalidade de consumo, Botsman e Roger (2011) em seus estudos identificaram quatro princípios essenciais, sendo eles: massa crítica, capacidade ociosa, crença nos bens comuns e confiança entre estranhos (Quadro 1).

\section{Quadro 1: Princípios de Consumo Colaborativo}

\begin{tabular}{|c|c|}
\hline Princípios & Definição \\
\hline Massa Crítica & $\begin{array}{l}\text { Termo sociológico usado para descrever a existência de um momento suficiente em } \\
\text { um sistema para torná-lo autossustentável. Sendo fundamental para o consumo } \\
\text { colaborativo pelas razões de escolha e prova social. Para que os usuários se sintam } \\
\text { satisfeitos, deve haver opções e disponibilidades de bens suficientes para uma escolha, } \\
\text { para fazer com que os usuários se sintam satisfeitos, caso contrário, o sistema será } \\
\text { mal utilizado e terá vida curta. A massa crítica de ferramentas/bens ou usuários difere } \\
\text { no que a empresa oferece e como a plataforma na qual está inserida é construída. }\end{array}$ \\
\hline Capacidade Ociosa & $\begin{array}{l}\text { É referida às coisas que possuímos com potencial altamente não utilizado que poderiam } \\
\text { ser utilizadas. O Consumo Colaborativo pega essa capacidade ociosa e a redistribui em } \\
\text { outros lugares por meio da tecnologia e redes sociais. }\end{array}$ \\
\hline Crença nos bens comuns & $\begin{array}{l}\text { Refere-se a um efeito de rede, em que todas as pessoas que ingressam ou usam } \\
\text { consumo colaborativo agregam valor a uma comunidade, física ou digital, e, portanto, } \\
\text { permitem que nosso próprio valor social se expanda em troca. }\end{array}$ \\
\hline Confiança em estranhos & $\begin{array}{l}\text { A confiança entre estranhos está nas plataformas de atuação em que o comércio e a } \\
\text { comunidade se encontram. }\end{array}$ \\
\hline
\end{tabular}

Fonte: Adaptado de Botsman e Roger (2011)

De acordo com os autores Botsman e Roger (2011), não existe princípio mais relevante que o outro. A compreensão desses elementos pode auxiliar os profissionais de marketing das empresas a 
desenvolverem melhores estratégias de posicionamento de mercado, tornando as empresas inovadoras e disruptivas. Além disso, essa configuração alternativa do consumo está atrelada ao fortalecimento do caráter experiencial do consumo e da busca de multi sensações e vivências que extrapolam a simples posse de um bem (HOLBROOK; HIRSCHMAN, 1982; SOUSA; MELO, 2018).

Belk (2014) afirma que o consumo colaborativo é um fenômeno intrínseco à era digital, embora a colaboração e o compartilhamento sejam fenômenos tradicionais, anteriores ao advento digital. Acreditase que o consumidor, ao adotar o comportamento de consumo colaborativo, tem como intuito a utilização do produto e a prestação de serviço, ou seja, o acesso aos bens e à experiência pelo tempo necessário de uso em vez de deter a posse permanente do objeto (BARDHI; ECKHARDT, 2012).

Apesar dessa modalidade de consumo ser intrínseca à era digital, ela não é uma nova tendência de nicho específica, nem uma mudança reacionária à recessão, mas sim um fenômeno socioeconômico que transforma a maneira como as empresas pensam sobre suas proposições de valor, que também modifica a forma de satisfazer as necessidades dos indivíduos, segundo (BOTSMAN; ROGERS, 2011).

Nos estudos realizados por Curth et al. (2021) a relação existente entre a intenção de compra e a identidade social das pessoas obtem um senso de pertencimento pela comunidade na qual convive durante um período de tempo indeterminado, gerando intenções comportamentais possitivas. Além disso, as premissas do consumo consciente de produtos e ou serviços podem auxiliar na participação positiva ou não daquela comunidade.

Sendo assim, as empresas passam a interagir com seus consumidores em busca de criar uma rede de comunicação para uma maior compreensão das necessidades dos clientes. Esse processo de interação entre empresa e consumidor para a geração de valor é conhecido como cocriação de valor.

\subsection{COCRIAÇÃO DE VALOR}

Com as mudanças na forma de consumir e com a interação entre empresa e consumidor, as empresas buscam cada vez mais soluções organizacionais para melhorar a experiência de consumo, e consequentemente, criar valor para o consumidor (NUNES; SILVEIRA, 2016; CIETTA, 2012; LIPOVETSKY, 2009). Dessa forma, a cocriação de valor surge para que as pessoas possam se expressar e compartilhar novas ideias para agregar valor e gerar novos produtos ou aperfeiçoar os existentes.

De acordo com Pellizzoni e Baldanza (2019) a cocriação de valor acontece quando a organização, antes centrada no produto, passa a ter uma visão centrada nas expectativas do consumidor. Essa mudança de visão empresarial produz uma abertura que possibilita a geração de valor na medida em que existe um cuidado com as expectativas do consumidor. Entretanto, de acordo com Prahalad e Ramaswamy (2004), essa transição não representa uma transferência das atividades para os clientes e fornecedores, nem a 
customização dos bens e serviços. E sim, irá permitir uma interface produtiva, com capacidade contínua de inovação e geração de lucros para uma empresa (PRAHALAD; RAMASWAMY, 2004).

Para que ocorra uma experiência positiva e produtiva, é necessário a criação de um ambiente onde os consumidores possam criá-la de forma única. Nesse sentido, Prahalad e Ramaswamy $(2002,2004)$ afirmam que essa experiência não pode ser comoditizada como os produtos e que representa uma fonte de vantagens competitivas. Nesse contexto, para que seja construído um ambiente propício, devem ser considerados basicamente quatro blocos fundamentais, que provam a cocriação (Quadro 2): Diálogo, Acesso, Avaliação de Risco e Benefícios e Transparência (DART), conforme Prahalad e Ramaswamy (2002, 2004).

\begin{tabular}{|l|l|}
\multicolumn{1}{|c|}{ Blocos } & \multicolumn{1}{c|}{ Quadro 2: Blocos de Cocriaçãóãa } \\
\hline Diálogo & $\begin{array}{l}\text { Diz respeito à substituição da comunicação unidirecional tradicional por processos que estimulem } \\
\text { o fluxo bidirecional de informações, promovendo maior interação e permitindo ao consumidor } \\
\text { assumir um papel ativo na criação da experiência (CALLEGARO; BRASIL, 2012). Ocorrendo assim, } \\
\text { uma relação de igualdade entre as partes envolvidas no processo. }\end{array}$ \\
\hline Acesso & $\begin{array}{l}\text { Oacesso se dá pela facilidade que o consumidor tem de consulta e alcance dos processos e recursos } \\
\text { utilizados na criação de valor e entrega de ofertas (ALBINSSON; PEREIRA; SAUTTER, 2016). }\end{array}$ \\
\hline $\begin{array}{l}\text { Avaliação de Risco e e } \\
\text { Benefícios }\end{array}$ & $\begin{array}{l}\text { O ato de informar o potencial de riscos e benefícios fortalece a relação de confiança entre a empresa } \\
\text { e os consumidores (TAGHIZADEH et al., 2016) e reduz a assimetria de informações percebida } \\
\text { (CALLEGARO; BRASIL, 2012). }\end{array}$ \\
\hline Transparência & $\begin{array}{l}\text { Apresentar aos consumidores informações do funcionamento do negócio. As empresas partilham } \\
\text { dados considerados sigilosos, por revelar aspectos do ambiente interno do negócio (ALBINSSON; } \\
\text { PEREIRA; SAUTTER, 2016). }\end{array}$ \\
\hline
\end{tabular}

\section{Fonte: Adaptado de Pellizzoni e Baldanza (2019)}

As atividades que estão relacionadas aos blocos de cocriação DART constituem um processo sistemático que pode transformar os esforços de consumo em vantagens competitivas exclusivas (TAGHIZADEH et al., 2016). Dessa forma, compreendendo a relação desses blocos, as empresas podem trabalhar a cocriação de valor. É notória a codependência desses blocos para que seja um espaço favorável à cocriação. Para que seja realizado um Diálogo de forma efetiva, o consumidor percebe o livre Acesso e a Transparência da empresa. Da mesma forma, o Acesso e a Transparência implicam a necessidade de informações associadas ao Risco e benefícios relacionados aos bens e serviços (PELLIZZONI; BALDANZA, 2019).

A cocriação de valor dentro do âmbito dos serviços altera as noções e padrões convencionais de valor e negócios. Corroborando para uma redefinição das relações entre consumidores e empresas, bem 
como das formas de consumo. Para que ela ocorra é preciso um diálogo maior entre as partes envolvidas, permitindo aos clientes personalizar um produto ou serviço que se encaixe às suas necessidades, o que leva a suposição de que eles estão dispostos a pagar mais pelo produto cocriado, e quando há este engajamento, há uma sensação de pertencimento ao processo da empresa que gera satisfação e lealdade aos serviços (GRISSEMANN; SAUER, 2012).

Os serviços são mais bem compreendidos em termos de estruturas de nível. Interações empresacliente ou fornecedor-empresa em um nível geram estruturas de nível micro, como normas empresacliente. Cumulativamente, essas estruturas de nível micro estruturas se desenvolvem em nível meso (por exemplo, indústria, comunidade de marca nidade) estruturas como significado da marca, símbolos e indústria padrões. Por sua vez, estes evoluem para o nível macro (por exemplo, culturais, sociais), como estruturas culturais generalizadas normas, linguagem e leis (GREER; VARGO; LUSCH, 2016).

Nesse sentido, segundo Oliveira, Damacena e Brambilla (2014), empresas que pretendem ser competitivas necessitam mais do que ser inovadoras em seus produtos e serviços, elas precisam inovar em todos os pontos que interagem com o mercado, tendo assim, o seu foco direcionado nas experiências. Ouvindo cada vez mais seus clientes e os satisfazendo conforme suas necessidades apontadas no processo de cocriação. Embora ouvir e consultar a opinião dos consumidores para desenvolvimento de novos produtos ou estratégias de marketing não seja novidade (BENDAPUDI; LEONE, 2003), o que vem mudando é a forma como as empresas criam um ambiente de rede e conexão com grandes grupos de consumidores, proporcionando assim, uma interação maior com eles, em trocas contínuas de valor. Os autores Prahalad e Ramaswamy (2002) direcionam, assim, o seu foco para as experiências dos consumidores.

Como exemplo de empresa que tem seu foco direcionado nas experiências, podemos destacar, dentro do segmento de hospedagens, a plataforma Airbnb que conecta viajantes em busca de acomodação a pessoas que desejam alugar seu espaço a fim de receber uma renda extra.

\subsection{AIRBNB}

O segmento do serviço, mais especificamente o setor da hospitalidade, desbravam desafios no tocante à crescente competitividade predominante do setor de hospedagem. As organizações buscam apoiar-se em estratégias digitais, bem como, alternativas colaborativas juntos aos usuários dos serviços de hospedagem (ABRASEL, 2016). De acordo com IBGE (2016), o setor de serviço (hospitalidade) obteve um faturamento de cerca de 170 bilhões que corresponde a 2,7\% do PIB de 2015. E, mesmo diante de pandemias, entre elas, a da Covid-19, existem autores tais como: Hajibaba et al. (2015) a nos indicar que 
os turistas emitem reações em relação aos seus hábitos e costumes, persistindo no ato de viajar mesmo em períodos conflituosos. As mudanças podem ocorrer, mas as viagens vão continuar a acontecer.

As mudanças sociais são constantemente alteradas de formas drásticas e com a mesma velocidade que os processos de tecnologia e oscilação econômica de um País. Nesse contexto, de mudanças, o mundo e os comportamentos de consumo vivenciam a cada dia os diversos cenários da inovação. A própria pandemia provocada pela Covid-19 passa a ser percebida conforme Higgins-Desbiolles (2020), como uma possibilidade de mudança de comportamentos reinventáveis no turismo, permitindo assim, novas perspectivas. Então, a motivação passa a estar relacionada de forma sugestiva ao ato de aproveitar a vida e se permitir à novas experiências.

Nesse mundo de mudança tecnológica confusa e muitas vezes incontroláveis, os seres humanos tendem a se reagrupar em torno de vínculos sociais afetivos primários como: religião, classe social, etnias entre outros. De fato, o dilema que percorre o termo da tecnologia diverse entre opiniões dos usuários, percebe-se que a tecnologia é a sociedade, todavia, a sociedade não pode ser compreendida ou interpretada sem os artefatos das ferramentas e aplicativos tecnológicos (CASTELLS, 2005).

O setor de hospedagem está sendo rapidamente transformado por serviço de hospedagem domiciliar online. Um dos maiores exemplos dessa mudança é a plataforma digital Airbnb, a qual surge como uma alternativa dentro dos serviços de hospedagens. Através dessa plataforma, os usuários podem se hospedar ou oferecer seus lares para hospedagem de outros usuários. O Airbnb ressignifica o modelo de proposta de valor de uma hospedagem convencional, uma vez que, os usuários buscam uma acomodação e não mais um estabelecimento convencional de hospedagem.

A empresa tem sede em São Francisco, Califórnia, e 34 escritórios no mundo, incluindo o Brasil, em São Paulo. O lançamento global da plataforma foi em 2018, e até 2019 atingiu o número de 500 milhões de hóspedes em 81.000 cidades em 191 países como uma rede de cerca de 4,5 milhões de anfitriões (AIRBNB, 2018). Por se tratar de uma rede intercedida por uma plataforma digital, ela pode ser vista como um negócio de tecnologia voltada ao setor de hospedagens.

O Airbnb com sua atuação global, ressignifica o modelo de proposta de valor de uma hospedagem convencional, modificando as relações entre oferta e demanda. Conectando viajantes a procura de experiências em seus locais de viagem a anfitriões com algum lugar ocioso em seus domicílios ou não, com intuito de renda extra, interação e novas experiências (OLIVEIRA, 2018).

Esse novo modelo de negócio oferece a oportunidade de experiência por meio da hospedagem alternativa. Com uso da internet, estes compartilhamentos transcendem a esfera local. Nesse sistema, o foco das trocas é a interação social (BOTSMAN; ROGERS, 2011). Dessa maneira, os usuários têm a oportunidade de ter uma maior interação com a realidade do local no qual desejam visitar. Garcia (2014, 
p. 17) enfatiza isso quando define a hospedagem alternativa como uma "estadia diferenciada, onde o visitante tem a oportunidade de integrar-se à rotina de uma casa, em um ambiente familiar, onde o tratamento assemelha-se à acolhida de um parente ou amigo".

Dentro do site ou do aplicativo do Airbnb, após a realização de uma cadastro, os usuário podem escolher o local onde irão se hospedar, de acordo com a localidade, preço, quantidade de hospedes, tipo de acomodação, entre outros filtros disponíveis, como por exemplo as comodidades (wifi, ar condicionado, secador, entre outros itens disponiveis). Para aqueles que desejam ofertar seus lugares, é necessário o preenchimento de alguns requisitos da plataforma, para se tornarem anfitriões, além disso, esses devem seguir as orientações oferecidas sobre como devem interagir e o compromisso de exercer mais do que uma simples hospedagem, e sim uma experiência.

Visando o aumento da segurança e da confiança, o Airbnb introduziu inúmeros mecanismos de verificação de identidade que incluem o fornecimento de identificação por foto, autenticação do número de telefone das partes, e conexão de perfil pessoal do Airbnb com outras contas de mídias sociais como o Facebook e Linkedin (AIRBNB, 2017).

Embora haja uma grande praticidade nesse tipo de serviço, o Airbnb não se responsabiliza pela conduta dos usuários, nem pela veracidade de informações postadas, "o hóspede assume todos os riscos pela reserva" (AIRBNB, 2018), uma vez que a plataforma surge apenas como uma facilitadora no processo de transição entre hóspede e anfitrião, não sendo regulada entre eles. De maneira geral, as responsabilidades do Airbnb limitam-se a facilitar a disponibilidade do site, do aplicativo e dos serviços e servir como "um agente limitado de cobrança de pagamentos exclusivamente com o propósito de receber as taxas de acomodação dos hóspedes" (AIRBNB, 2017).

\section{METODOLOGIA}

A natureza deste estudo é descritiva com abordagem quantitativa, onde o método utilizado para o levantamento dos dados foi tipo survey. Para alcançar os objetivos propostos neste artigo foi necessário realizar o levantamento das informações sobre os componentes da escala DART, logo, foi aplicado um questionário baseado em estudos anteriores realizados por outros autores sobre a temática, ou seja, instrumento validado. A pesquisa quantitativa tem como objetivo identificar ou investigar a relação entre os constructos e variáveis identificadas pela revisão literária, causadas pelo fenômeno (MALHOTRA, 2012).

$O$ instrumento de coleta de dados foi desenvolvido em duas seções sendo a primeira com questões sociodemográficas, para verificação dos dados como idade, sexo, estado civil, ocupação e renda, e na segunda contendo questões extraídas da escala desenvolvida por Albinsson, Pereira, e Sautter (2016) 
e validada no Brasil por Pellizzoni e Baldanza (2019) onde são analisados os fatores Diálogo, Acesso, Avaliação de Risco e Transparência (Quadro 3), na qual os itens foram devidamente postos numa escala Likert de concordância variando de 0 a 10. A natureza descritiva das variáveis relacionadas por meio da revisão literária determinam qual a técnica estatística mais adequada (HAIR, 2009).

\begin{tabular}{|c|c|}
\hline CONSTRUTO & ITEM \\
\hline DIÁLOGO & $\begin{array}{l}\text { 1. O negócio parece aberto a receber informações sobre como melhorar minha experiência } \\
\text { com o serviço. }\end{array}$ \\
\hline DIÁLOGO & $\begin{array}{l}\text { 2. Vejo que o negócio está interessado em comunicar com os consumidores sobre as melho- } \\
\text { res formas de planejar e entregar um serviço de qualidade. }\end{array}$ \\
\hline DIÁLOGO & $\begin{array}{l}\text { 3. Percebo que o negócio usa diversos canais de comunicação para encorajar trocas de ideias } \\
\text { com os consumidores. }\end{array}$ \\
\hline DIÁLOGO & $\begin{array}{l}\text { 4. Sinto que posso conversar com o negócio sobre como agregar valor ao serviço que irão } \\
\text { prestar. }\end{array}$ \\
\hline ACESSO & 5. O negócio apresenta várias opções para que a sociedade decida como irá participar. \\
\hline ACESSO & 6. É fácil participar do negócio quanto, onde e como as pessoas quiserem. \\
\hline RISCOS E BENEFÍCIOS & 7. Fui informado sobre os riscos do negócio. \\
\hline RISCOS E BENEFÍCIOS & 8. Recebi informações sobre os benefícios do negócio. \\
\hline RISCOS E BENEFÍCIOS & 9. As informações que recebi do negócio são suficientes para decidir se quero ou não apoiá-lo. \\
\hline TRANSPARÊNCIA & 10. Compreendo as informações sobre o negócio. \\
\hline TRANSPARÊNCIA & $\begin{array}{l}\text { 11. Percebo que o negócio está disposto a me dar mais informações sobre o serviço, caso eu } \\
\text { solicite. }\end{array}$ \\
\hline TRANSPARÊNCIA & 12. Considero que minhas opiniões sobre o negócio serão respeitadas. \\
\hline TRANSPARÊNCIA & $\begin{array}{l}\text { 13. O negócio informa quais os custos envolvidos na concepção e entrega do serviço para a } \\
\text { sociedade. }\end{array}$ \\
\hline
\end{tabular}

Fonte: Adaptado de Pellizzoni e Baldanza (2018)

Após a definição dos construtos e variáveis a serem analisadas, procedeu-se à montagem do questionário. Posteriormente, o instrumento foi submetido a um pré-teste com cinco pessoas para corrigir eventuais erros de concordância e entendimento dos itens. O feedback do pré-teste foi favorável à continuidade da pesquisa. Para a aplicação e coleta dos dados utilizou-se a plataforma online Google Forms, onde os formulários foram encaminhados através de link, no período de novembro de 2019 a janeiro de 2020, de maneira individual para os respondentes por mensagem direcionada, além de posts em grupos de usuários da plataforma Airbnb no Facebook. A amostra foi composta de 310 respostas, e com o tratamento de missing values e outliers, totalizou 306 respostas válidas. 
Os dados coletados foram exportados para uma planilha do Excel, tratados para a obtenção das análises estatísticas. O software estatístico SPSS foi utilizado para análise de consistência da escala por meio de análise fatorial confirmatória, alpha de Cronbach e correlação de Pearson. Posteriormente, as variáveis foram agrupadas considerando a média e extraídas as medidas de posição (média e mediana), medidas de forma (assimetria e curtose), e a medida de dispersão (desvio-padrão). Adicionalmente foram desenvolvidas tabelas cruzadas entre os construtos da escala e os dados sócio demográficos.

Para análises dos resultados, optou-se por considerar como parâmetros nas medidas de posição: 0-3 (nível baixo), 4-7 (nível moderado) e 8-10 (nível alto). Quanto às medidas de assimetria e curtose, foram considerados como parâmetro de normalidade para assimetria 0 e para curtose 3. Para o desviopadrão, considerou-se até 1 como baixa dispersão, para valores entre 1,1 e 1,3 a dispersão foi considerada moderada, e acima de 1,4 como alta.

\section{RESULTADOS E DISCUSSÃO}

\subsection{PERFIL DA AMOSTRA}

A amostra foi composta por 310 usuários, correspondente a 100\% das respostas válidas. Desse total, 50,6 \% são do sexo feminino e 49,4\% são do sexo masculino. No tocante à idade, a maior faixa etária entre 26 e 30 anos teve maior representatividade com 31\%. Quanto ao estado civil dos respondentes, sua maioria é solteira $(61,9 \%)$, enquanto $9,4 \%$ são divorciados e os demais são casados ou possuem uma união estável. Este resultado diverge um pouco do estudo realizado por Pellizzoni e Baldanza (2018), pelo fato de, no grupo de negócios convencionais realizados em estudos anteriores, os homens (sexo masculino) representaram $(63,8 \%)$ superando o percentual do sexo feminino.

Quanto ao nível de escolaridade, observou-se que $54,8 \%$ dos usuários possuem pós-graduação e $36 \%$ nível superior. Quanto à renda e ocupação, a maior parte $(41,9 \%)$ recebe de 3 a 4 salários mínimos, e tem como sua fonte de renda o emprego em uma empresa privada $(35,2 \%)$.

\subsection{ANÁLISE DA ESCALA}

Para a análise exploratória dos dados, foi realizada a consistência psicométrica dos construtos por meio do alpha de Cronbach que, segundo Hair et al. (2009), é desejável acima de 0,60. Na amostra em questão, o alpha total deu 0,899 mostrando consistência em todos os construtos. Este resultado converge com o estudo realizado por Pellizzoni e Baldanza (2018), onde a confiabilidade da escala, por meio do alfa de Cronbach, foi de 0,849 aumentando significativamente a variância total dos dados. 
$\mathrm{Na}$ análise fatorial, verifica-se se algum dos itens dos construtos está mensurando fatores diferentes dos demais itens. Em caso positivo, pode ser feita a retirada do item, para melhorar a qualidade da escala. Para cada construto, foram realizados os testes KMO e de esfericidade de Bartlett, para verificar a adequação dos dados para a realização da análise fatorial.

A partir da análise, observou-se que o construto diálogo obteve um KMO de 0,757 e o teste de esfericidade se mostrou estatisticamente significativo (qui-quadrado=437,374; p-valor=0,000), demonstrando adequação para a análise fatorial. As comunalidades das variáveis D5 e D6 deram muito baixas, portanto, optou-se pela exclusão do item. Comparando com os resultados gerados do estudo de Pellizzoni e Baldanza (2018), O primeiro construto Diálogo do teste KMO foi de 0,825, e o teste de esfericidade foi estatisticamente significativo (qui-quadrado = 294,272; p-valor =0,000), o que indicou sua adequação para análise fatorial. Isso pode indicar a semelhança entre os resultados encontrados. Corroborando, promove maior interação e permitindo ao consumidor assumir um papel ativo na criação da experiência (CALLEGARO; BRASIL, 2012).

O construto acesso obteve um KMO de 0,500 com esfericidade também significativa (quiquadrado=129,114; $\mathrm{p}$-valor=0,000), mostrando também a adequação do construto para a análise fatorial. Na extração dos escores fatoriais, todas as comunalidades foram acima de 0,5. Os resultados apresentados Pellizzoni e Baldanza (2018), o construto acesso mostra o teste KMO que rendeu um resultado de 0,500, e o teste de esfericidade de Bartlett revelou significância estatística suficiente dos dados para realizar a análise fatorial (qui-quadrado $=12,394$, p-valor $=0,000$ ), os dados encontrados mostram semelhança entre os estudos. Corroborando, o construto acesso determina-se pela facilidade que o consumidor tem de consulta e alcance dos processos e recursos utilizados na criação de valor e entrega de ofertas (ALBINSSON; PEREIRA; SAUTTER, 2016).

No construto riscos e benefícios, o KMO foi de 0,671 com esfericidade significativa (quiquadrado=203,221; -valor=0,000), as comunalidades das variáveis R4 e R5 também se apresentaram abaixo de 0,5, portanto optou-se pela retirada dos itens. De acordo com Pellizzoni e Baldanza (2018), para o construto Risco e benefício, o teste KMO rendeu 0,668, e o teste de esfericidade de Bartlett foi considerado aceitável (qui-quadrado $=93.132 ; \mathrm{p}$-valor $=0,000$ ). Os resultados encontrados mostram convergência com nivel de explicação do construto significativo. Corroborando, o ato de informar o potencial de riscos e benefícios fortalece a relação de confiança entre a empresa e os consumidores (TAGHIZADEH et al., 2016).

0 construto transparência teve um $\mathrm{KMO}=0,781$ com esfericidade significativa (quiquadrado=449,434; p-valor=0,000). Comparando com Pellizzoni e Baldanza (2018), a análise do construto Transparência rendeu um KMO aceitável de 0,600, e foi considerado adequado para a análise fatorial pelo teste de esfericidade de Bartlett (qui-quadrado =139,591; e p-valor =0,000). Os dados encontrados 
mostram semelhança entre os estudos. Corroborado, apresentar aos consumidores informações acerca do funcionamento do negócio, partilhando dados considerados sigilosos, para revelar aspectos do ambiente interno do negócio (ALBINSSON; PEREIRA; SAUTTER, 2016).

Considerando as análises e adequações realizadas na análise fatorial, os itens foram agregados por meio do cálculo da média dos escores por respondente. Na correlação de Pearson, não houve indicativos de multicolinearidade, ou seja, todos os índices ficaram abaixo de 0,7. Os resultados estão na Tabela 1.

\begin{tabular}{l|r|r|r|r|r|r|r|r|r|r|r|r|r}
\hline & \multicolumn{1}{|c|}{ T1 } & D2 & D3 & D4 & A1 & A2 & R1 & R2 & R3 & T1 & T2 & T3 & T4 \\
\hline D1 & 1 & & & & & & & & & & & & \\
\hline D2 &, $624^{* *}$ & 1 & & & & & & & & & & & \\
\hline D3 &, $475^{* *}$ &, $534^{* *}$ & 1 & & & & & & & & & & \\
\hline D4 &, $571^{* *}$ &, $466^{* *}$ &, $558^{* *}$ & 1 & & & & & & & & & \\
\hline A1 &, $366^{* *}$ &, $415^{* *}$ &, $638^{* *}$ &, $553^{* *}$ & 1 & & & & & & & & \\
\hline A2 &, 100 &, $253^{* *}$ &, $381^{* *}$ &, $324^{* *}$ &, $589^{* *}$ & 1 & & & & & & & \\
\hline R1 &, $431^{* *}$ &, $298^{* *}$ &, $373^{* *}$ &, $530^{* *}$ &, $374^{* *}$ &, $121^{*}$ & 1 & & & & & & \\
\hline R2 &, $430^{* *}$ &, $450^{* *}$ &, $489^{* *}$ &, $423^{* *}$ &, $293^{* *}$ &, $221^{* *}$ &, $410^{* *}$ & 1 & & & & & \\
\hline R3 &, $522^{* *}$ &, $371^{* *}$ &, $361^{* *}$ &, $498^{* *}$ &, $379^{* *}$ &, $220^{* *}$ &, $541^{* *}$ &, $499^{* *}$ & 1 & & & & \\
\hline T1 &, $582^{* *}$ &, $548^{* *}$ &, $445^{* *}$ &, $482^{* *}$ &, $388^{* *}$ &, $177^{* *}$ &, $382^{* *}$ &, $541^{* *}$ &, $565^{* *}$ & 1 & & & \\
\hline T2 &, $492^{* *}$ &, $424^{* *}$ &, $467^{* *}$ &, $589^{* *}$ &, $457^{* *}$ &, $211^{* *}$ &, $457^{* *}$ &, $398^{* *}$ &, $535^{* *}$ &, $554^{* *}$ & 1 & & \\
\hline T3 &, $594^{* *}$ &, $525^{* *}$ &, $510^{* *}$ &, $631^{* *}$ &, $426^{* *}$ &, $199^{* *}$ &, $427^{* *}$ &, $443^{* *}$ &, $521^{* *}$ &, $609^{* *}$ &, $688^{* *}$ & & \\
\hline T4 &, $358^{* *}$ &, $326^{* *}$ &, $402^{* *}$ &, $351^{* *}$ &, $470^{* *}$ &, $142^{*}$ &, $455^{* *}$ &, $360^{* *}$ &, $453^{* *}$ &, $465^{* *}$ &, $414^{* *}$ &, $464^{* *}$ & 1 \\
\hline
\end{tabular}

\section{Fonte: Dados da pesquisa (2020)}

** A correlação é significativa no nível 0,01 (2 extremidades).

* A correlação é significativa no nível 0,05 (2 extremidades).

\subsection{ANÁLISES DAS VARIÁVEIS}

Para a análise dos construtos da escala: Diálogo, Acesso, Avaliação de Risco e Transparência (DART), a fim de compreender como cada item se comporta, foram extraídas as médias de posição, dispersão e forma. Sendo estas respectivamente, média e mediana, desvio padrão, assimetria e curtose, conforme a Tabela 2. 
Tabela 2: Análise das variáveis da Escala DART

\begin{tabular}{l|c|c|c|c|c}
\hline \multicolumn{1}{c|}{ Construtos } & Média & Mediana & Desvio Padrão & Assimetria & Curtose \\
\hline DIÁLOGO & 8,430 & 8,750 & 1,169 & $-1,336$ & 2,219 \\
\hline ACESSO & 7,570 & 8,000 & 1,739 & $-1,053$ & 1,017 \\
\hline RISCO & 8,215 & 8,666 & 1,526 & $-1,247$ & 1,422 \\
\hline TRANSPARÊNCIA & 8,722 & 9,000 & 1,185 & $-1,502$ & 3,098 \\
\hline
\end{tabular}

Fonte: Dados da pesquisa (2020)

O construto que apresentou maior média foi a Transparência, com 8,722. Seguida do Diálogo, com 8,430, o construto de Acesso foi o menos percebido pelos entrevistados, sendo sua média 7,570. Portanto, nota-se que a Transparência é importante nesse tipo de negócio colaborativo, e que o Diálogo é também um fator de relevância, uma vez que, ocorre a substituição da comunicação tradicional, unidirecional, por processos de fluxo bidirecional de informações, promovendo maior interação e permitindo ao consumidor assumir um papel ativo na criação da experiência (CALLEGARO; BRASIL, 2012).

Quanto à mediana, as variáveis que apresentaram o maior valor também foram Transparência e Diálogo, com 9,000 e 8,750, respectivamente. Sendo Acesso o menos relevante. Os respondentes compreendem as informações sobre a plataforma, como os custos envolvidos na concepção e entrega do serviço para a sociedade, além disso, percebem que a plataforma está aberta receber informações sobre como melhorar a experiência dos clientes com o serviço, e a dar mais informações sobre o serviço, caso solicite. Percebem também a abertura da plataforma em receber informações sobre como melhorar a experiência dos clientes com o serviço (PELLIZZONI; BALDANZA, 2019).

Quanto à medida de dispersão, desvio padrão, que mostra o quanto os dados estão dispersos ou mais concentrados, observa-se que o construto de Acesso teve o maior desvio padrão $(1,739)$ e que Diálogo teve o menor com 1,169. E quanto às medidas de forma, os construtos apresentaram uma certa assimetria à esquerda. Já a curtose ficou dentro dos parâmetros utilizados.

No tocante a curtose, que sugere o grau de achatamento da curva, a variável de Transparência apresentou o maior número (3,098), seguida do Diálogo com 2,019. E por último temos a variável de Acesso com 1,017. Dessa forma, as análises dos construtos apontam a importância de cada item na percepção dos usuários da plataforma e é notória a codependência desses blocos para que seja um espaço favorável à cocriação de valor. 


\subsection{TABELAS CRUZADAS}

Para ampliar os efeitos de análises, as tabelas cruzadas mesclaram dados sócio demográficos de idade, sexo e renda com os construtos, tendo como referência as médias. Ao realizar a análise entre os construtos e idade, observou-se que o construto 'transparência' obtevemaiores médias em quase todas as faixas etárias, com exceção entre pessoas com 18 a 20 anos.

Esse resultado denota que ao utilizar um serviço colaborativo, como é o caso do Airbnb, as pessoas tendem a reconhecer muito o nível de segurança oferecido se importando muito com o quanto o seviço presta contas e apresenta o negócio (ALBINSSON; PEREIRA; SAUTTER, 2016). Além do mais, o nível de importância da transparência organizacional tende a ser maior entre pessoas com mais de 30 anos (Tabela 3).

Tabela 3: Idade x Cocriação

\begin{tabular}{l|c|c|c|c}
\hline Idade & Diálogo & Acesso & Riscos/benefícios & Transparência \\
\hline $18-20$ anos & 8,54 & 7,55 & 7,97 & 8,52 \\
\hline $21-25$ anos & 8,16 & 7,44 & 7,88 & 8,51 \\
\hline $26-30$ anos & 8,46 & 7,69 & 8,31 & 8,75 \\
\hline $31-35$ anos & 8,57 & 7,67 & 8,48 & 8,91 \\
\hline mais de 35 anos & 8,50 & 7,37 & 8,21 & 8,78 \\
\hline Total Geral & $\mathbf{8 , 4 2}$ & $\mathbf{7 , 5 7}$ & $\mathbf{8 , 2 2}$ & $\mathbf{8 , 7 2}$ \\
\hline
\end{tabular}

Fonte: Dados da pesquisa (2020)

Observa-se ainda que o público entre 31 e 35 anos obteve maiores médias nos construtos diálogo, riscos/benefícios e transparência, o que pode significar que essa faixa etária é mais criteriosa com a utilização do serviço e valoriza mais a cocriação do que as demais faixas etárias. Outro ponto de destaque é que o construto 'acesso' teve maior média entre o público de 26 a 30 anos, fato que pode ser explicado pela grande necessidade de interação entre pessoas mais jovens.

Complementando as análises, foi realizado o cruzamento entre sexo e os quatro construtos de cocriação. Na tabela 4, observa-se que o público masculino obteve maiores médias em todos os construtos do que o público feminino. A partir disso, pode-se inferir que as mulheres tendem a ser mais exigentes quanto às ferramentas disponíveis para a cocriação do Airbnb do que os homens. E em ambos os sexos, o construto transparência também teve maiores médias, ratificando a importância desse construto para a cocriação. 


\begin{tabular}{l|c|c|c|c}
\multicolumn{7}{c}{ Tabela 4: Sexo x Cocriação } \\
\hline Sexo & Diálogo & Acesso & Riscos/benefícios & Transparência \\
\hline Feminino & 8,31 & 7,43 & 8,08 & 8,63 \\
\hline Masculino & 8,54 & 7,72 & 8,36 & 8,82 \\
\hline Total Geral & $\mathbf{8 , 4 2}$ & $\mathbf{7 , 5 7}$ & $\mathbf{8 , 2 2}$ & $\mathbf{8 , 7 2}$ \\
\hline
\end{tabular}

Fonte: Dados da pesquisa (2020)

No cruzamento entre renda e cocriação, observa-se na Tabela 5 que pessoas com rendas mais baixas tiveram médias maiores e à medida que a renda vai subindo, as médias foram diminuindo. Por meio dessa análise é possivel inferir que pessoas com poder aquisitivo maior tendem a demandar por mais contato e personalização para cocriarem.

Tabela 5: Renda x Cocriação

\begin{tabular}{l|c|c|c|c}
\hline Renda & Diálogo & Acesso & Riscos/benefícios & Transparência \\
\hline Menos de um salário-mínimo & 8,69 & 7,35 & 8,49 & 8,88 \\
\hline De 1 salário até 2 salários & 8,53 & 7,77 & 8,36 & 8,86 \\
\hline De 3 salários até 4 salários & 8,46 & 7,50 & 8,29 & 8,76 \\
\hline Mais de 5 salários & 7,86 & 7,41 & 7,41 & 8,15 \\
\hline Total Geral & $\mathbf{8 , 4 2}$ & $\mathbf{7 , 5 7}$ & $\mathbf{8 , 2 2}$ & $\mathbf{8 , 7 2}$ \\
\hline
\end{tabular}

Fonte: Dados da pesquisa (2020)

É importante destacar que também nessa perspectiva de renda, o construto transparência obteve maiores médias entre todos as faixas salariais, seguido do construto transparência. Portanto, além de elucidar a funcionalidade do serviço e o papel social do mesmo, é importante manter uma abertura à comunicação bilateral entre empresa e usuário.

\section{CONSIDERAÇÕES FINAIS}

O presente estudo abordou o consumo colaborativo, no que diz respeito à cocriação do valor na utilização da plataforma de hospedagem Airbnb. Nesse contexto, buscou analisar quais aspectos da cocriação de valor mais influenciam o comportamento de consumidores de um negócio colaborativo de hospedagem de acordo com a escala DART (Diálogo, Acesso, Avaliação de Risco e Transparência).

Quanto aos principais resultados da pesquisa, observou-se que os usuários pertencentes à amostra são, em sua maioria, mulheres solteiras entre 26 e 30 anos, tendo pós-graduação, recebendo de 3 a 4 salários mínimos em uma empresa privada. Frente às questões de cocriação de valor, de acordo com 
os resultados obtidos, os fatores da escala DART que são mais percebidos, consequentemente mais relevantes para os usuários da plataforma estudada, foram: Transparência e Diálogo.

Dessa forma, os usuários percebem a Transparência e Diálogo como principais fatores de cocriação de valor dentro do segmento de hospedagem colaborativa. Para eles, o Airbnb está aberto a receber informações sobre como melhorar a experiência dos clientes com o serviço e cada vez mais interessado em se comunicar com os consumidores, além de passar todas as informações relativas aos custos envolvidos na entrega do serviço para sociedade.

Por meio das tabelas cruzadas, observou-se que pessoas do sexo feminino, mais jovens e com maiores rendas tendem a ser mais exigentes quanto ao processo de cocriação de valor. Isso pode representar importantes indicativos de atuação para melhorar a performance de aproximação nesse tipo de negócio. É possivel que isso se explique pelo fato de se tratar de compartilhamento de uso dos estabelecimentos. Portanto, vale examinar se esse comportamento se repete também em estabelecimentos de hospedagem convencionais.

Do ponto de vista empresarial, para que as empresas se tornem mais inovadoras e competitivas, elas precisam se preocupar com a cocriação de valor, entendendo quais os principais fatores do processo de cocriação são mais relevantes para seus usuários, direcionando seu foco para as experiências, ouvindo cada vez mais seus clientes, para que suas necessidades sejam satisfeitas de acordo com o processo de cocriação de valor.

Com relação às limitações do estudo, destaca-se a dependência da voluntariedade dos respondentes, uma vez que a maioria dos participantes foram convidados a participar da pesquisa por meio de posts em grupos do Facebook sobre Airbnb. Esse fator fez com que a pesquisa fosse estendida por um período maior do que o previsto, além de possuir um filtro (uso do Airbnb) difícil de ser alcançado, por ser uma plataforma recente no Brasil. No entanto, a amostra foi composta por um número superior a 200, quantidade recomendada para análises estatísticas mais robustas.

Sugere-se a aplicação desta pesquisa a uma realidade pós-pandemia, pois, no período pandêmico, surge a implicância de novas análises que acrescentariam no desenvolvimento da investigação e prováveis modificações aos seus resultados; entre eles, os indicadores da pesquisa eatualização do acervo decorrente de conteúdos teóricos e de novas pesquisas que possam contribuir, em decorrência do período. Isso em decorrência de que receber pessoas vindas de outros lugares aumenta o nível de insegurança, mesmo com protocolos de testes negativos, uma vez que o nível de contaminação da Covid-19 é muito alto. Essa insegurança também pode ser percebida pelos hóspedes, uma vez que a perspectiva de colaboração fica comprometida em virtude do distancimento social. 
Academicamente, a pesquisa contribui com o estudo do consumo colaborativo e da cocriação de valor, destacando a exploração dos quatros blocos propostos por Prahalad e Ramaswamy (2001) e escala desenvolvida por Albinsson (2015). Além disso, almeja-se que o estudo desperte o interesse de outros pesquisadores a respeito do assunto abordado. Sugere-se que em estudos futuros sejam utilizadas outras plataformas de consumo colaborativo, visto o crescimento constante dessa prática em diferentes âmbitos do consumo, sendo relevante a compreensão das semelhanças e das diferenças entre eles.

\section{REFERÊNCIAS}

AIRBNB. Airbnb comemora o marco de 500 millhões de chegadas de hóspedes. 2019. Disponível em: https://news.airbnb.com/br/airbnb-comemora-0-marco-de-500-milhoes-de-chegadas-de-hospedes/. Acesso em: 10 fev. 2020.

ALBINSSON, Pia A.; PERERA, B. Yasanthi; SAUTTER, Pookie Truly. DART scale development: diagnosing a firm's readiness for strategic value co-creation. Journal of Marketing Theory and Practice, v. 24, n. 1, p. 42-58, 2016.

BARDHI, Fleura; ECKHARDT, Giana M. Access-based consumption: The case of car sharing. Journal of consumer research, v. 39, n. 4, p. 881-898, 2012.

BELK, Russell. You are what you can access: Sharing and collaborative consumption online. Journal of business research, v. 67, n. 8, p. 1595-1600, 2014.

BELK, Russell. Why not share rather than own? The Annals of the American Academy of Political and Social Science, v. 611, n. 1, p. 126-140, 2007.

BENDAPUDI, Neeli; LEONE, Robert P. Psychological implications of customer participation in co-production. Journal of marketing, v. 67, n. 1, p. 14-28, 2003.

BRAMBILLA, Flávio Régio et al. Cocriação e confiança percebida: relações em um cenário de inovação disruptiva de serviço. Caderno Profissional de Marketing-UNIMEP, v. 5, n. 3, p. 75-88, 2017.

BOTSMAN, R.; ROGERS, R. What's mine is yours: How collaborative consumption is changing the way we live. 304p. London: Collins, 2011.

CALLEGARE, Ana Rita Catelan; BRASIL, Vinícius Sittoni. A gestão da experiência do cliente no varejo. REBRAE, v. 5, n. 2, p. 207-220, 2012. 
CASTELLS, Manuel et al. A sociedade em rede: do conhecimento à política. In: CASTELLS, Manuel; CARDOSO, Gustavo (Orgs.). A sociedade em rede: do conhecimento à acção política. Lisboa: Imprensa Nacional - Casa da Moeda, 2005. p. 17-30.

CIETTA, E. A Revolução do fast-fashion: estratégias e modelos organizativos para competir nas indústrias híbridas. São Paulo: Estação das Letras e Cores, 2012.

CURTH, Marcelo; SILVEIRA, Alexandre Borba; PINHEIRO, Juciele Pires. Comunidades verdes mobile: um estudo sobre a relação da identidade social e a intenção de compra. Revista Gestão e Desenvolvimento, v. 18, n. 1, p. 172-193, 2021.

FARIAS, Miriam Leite et al. Explicando o consumo colaborativo por meio do modelo tar: uma aplicação com usuários do Airbnb. In: CLAV - CONGRESSO LATINO-AMERICANO DE VAREJO, 13., 2018. São Paulo. Anais... São Paulo: FGV, 2018.

GARCIA, Ana Paula da Matta et al. Os desafios do planejamento da comunicação para implementação de um programa de hospedagem alternativa: o estudo de caso do Projeto "cama e café" de Brasília. 2020 .

GIL, Antonio Carlos. Métodos e Técnicas de Pesquisa Social. 6 ed. São Paulo: Atlas, 2009.

GREER, Charles R.; LUSCH, Robert F.; VARGO, Stephen L. A service perspective. Organizational dynamics, v. 1, n. 45, p. 28-38, 2016.

GRISSEMANN, Ursula S.; STOKBURGER-SAUER, Nicola E. Customer co-creation of travel services: The role of company support and customer satisfaction with the co-creation performance. Tourism management, v. 33, n. 6, p. 1483-1492, 2012.

GRÖNROOS, C. Marketing: Gerenciamento e Serviços. Rio De Janeiro: Elsevier, 2009.

HAIR, Joseph F. et al. Análise Multivariada de Dados. Bookman Editora, 2009.

HAJIBABA, H., Gretzel, U., Leisch, F., Dolnicar, S. Crisis-resistant tourists. annals of tourism research, 53, 46-60, 2015.

HAMARI, J.; Sjöklint, M.; Ukkonen, A. The sharing economy: why people participate in collaborative consumption. Journal of the association for information science and technology, p. 1-19, 2015.

HIGGINS-DESBIOLLES, Freya. Socialising tourism for social and ecological justice after COVID-19. Tourism Geographies, v. 22, n. 3, p. 610-623, 2020. 
HOLBROOK, M. B.; Hirschman, E. C. The experiential aspects of consumption: consumer fantasies, feelings, and fun. Journal of Consumer Research, 9(2), 132-140, 1982.

LAMBERTON, C. P.; ROSE, R. L. When is ours better than mine? A framework for understanding and altering participation in commercial sharing systems. Journal of Marketing, 76(4), 109-125, 2012.

MALHOTRA, N. K. Pesquisa De Marketing: Uma Orientação Aplicada. Bookman Editora 2001.

NUNES, M. P.; DA SILVEIRA, G. A. Análise das motivações do consumidor de fast-fashion. Revista de Administração Imed, 6(1), 56-71, 2016.

OLIVEIRA, Nathan Marques et al. Airbnb em Itaipulândia/PR: cocriando valor por meio da infraestrutura de hospedagem alternativa, 2018.

OLIVEIRA, G; Damacena, C.; Brambilla, F. R. Cocriação como proposta para geração de valor: caso da empresa dental américa. Desenvolve: Revista de Gestão do Unilasalle, v. 3, n. 2, p. 129-150, 2014.

OWYANG, Jeremiah; SAMUEL, Alexandra. The new rules of the collaborative economy. Vision Critical, v. 28, 2015.

PELLIZZONI, L. N.; BALDANZA, R. F. Co-creation in conventional and collaborative businesses. Estudios Gerenciales, v. 35, p. 95-108, 2019.

PISCICELLI, L.; COOPER, T.; FISHER, T. The role of values in collaborative consumption: insights from a produtct-service system for lending and borrowing in the uk. Journal of Cleaner Production, v. 97, p. 2129, 2015.

PIZZOL, H. O. D. Proposição de uma escala para mensuração do consumo colaborativo: compreendendo o compartilhamento de bens e a sua relação com os valores pessoais master's thesis. Porto Alegre: Pontifícia Universidade Católica do Rio Grande do Sul. 2015.

ROSS, D.; HAHN, R. Does shared consumption affect consumers' values, attitudes, and norms? a panel study. Journal of Business Research, v. 77, p. 113-123, 2017.

STANKOV, U.; FILIMONAU, V.; VUIIČIĆ, M. D. A mindful shift: an opportunity for mindfulness-driven tourism in a post-pandemic world. Tourism Geographies, 22(3), 703-712, 2020.

DE SOUSA, João Henriques; MELO, Francisco Vicente Sales. Moda "Só para Maiores": experiência de consumo de pessoas obesas em lojas especializadas de vestuário plus size. Revista Administração em Diálogo, v. 20, n. 3, p. 110-123, 2018. 


\section{Gestãoe \\ Desenvolvimento}

e-ISSN: 2446-6875

p-ISSN: $1807-5436$

TAGHIZADEH, S. K.; JAYARAMAN, K.; ISMAIL, I.; RAHMAN, S. A. Scale development and validation for dart model of value co-creation process on innovation strategy. Journal of Business e Industrial Marketing, 31(1), 24-35, 2016.

UBAL, Valentina Ortiz; LAZARIN, Lucas Roecker. Optar pelo consumo colaborativo pode aumentar seu bem-estar? Revista Administração em Diálogo - Rad, [s.I.], v. 21, n. 2, p. 215-239, jun. 2019. Issn 2178-0080. Disponivel em: http://ken.pucsp.br/rad/article/view/39719/28944. Acesso em: 22 jan. 2020. Doi: https://doi.org/10.23925/2178-0080.2019v21i2.39719. 